\title{
Testing Real-World Application of Appropriateness Criteria of Single Photon Emission Computed Tomography (SPECT) In Two Egyptian Hospitals
}

\author{
Adham Abdeltawab* ${ }^{*}$, Hazem Mansour and Mona Rayan
}

\begin{abstract}
Background: The American College of Cardiology pioneered appropriateness criteria for single-photon emission computed tomography myocardial perfusion imaging in 2005 to account for evidence-based clinical relevance of stress perfusion imaging.

Our aim was to assess and compare appropriateness use criteria in in Kobry al Kobba military hospital and Ain Shams University hospitals.

Methods: All patients were subjected to thorough history taking, calculation of pretest probability and Framingham risk score, determination of appropriateness use criteria and stress-rest Tc $99 \mathrm{~m}$ imaging to detect the presence of ischemia and one day Tc $99 \mathrm{~m}$ imaging to detect viability.

Results: The study included 442 patients with mean age of 56.5 years, with male predominance (77\%), 38\% were diabetics and $58 \%$ had hypertension.

Seventy-eight percent of patients had appropriate tests, uncertain tests in 12\% and 10\% inappropriate studies. 47\% of appropriate tests show positive results of SPECT.

Conclusion: We concluded that appropriateness criteria are effective in identifying appropriateness of SPECT in a diverse patient population.
\end{abstract}

Keywords: SPECT, MPI, stress, Coronary artery disease, viability test

\section{Background}

There has recently been an explosive growth in cardiovascular imaging, with stress testing demonstrating $6.1 \%$ annual increase versus $2 \%$ for cardiac catheterization, $0.8 \%$ for percutaneous intervention, and $0.1 \%$ for acute myocardial infarctions in population-based study of the United States Medicare patients [1] [2].

The American College of Cardiology pioneered appropriateness criteria for single-photon emission computed tomography (SPECT) myocardial perfusion imaging (MPI) in 2005 [1]. The criteria were developed to account for evidence-based clinical relevance of stress

\footnotetext{
*Correspondence: Adham_abdeltawab@med.asu.edu.eg; adham1st@yahoo.com

Cardiology Department, Ain Shams University Hospitals, Faculty of Medicine, Ain Shams University, Abbassia, Cairo P.O. 11381, Egypt
}

perfusion imaging and were the first cardiology specific document to address appropriateness. The criteria relied on the modified RAND/UCLA methodology to identify 52 common clinical scenarios and was divided into appropriate, uncertain, and inappropriate indications $[1,3]$.

New designations were suggested for some indications when SPECT criteria were reviewed in 2007 [4]. An update on appropriateness criteria was published in May 2009 [5].

Despite these developments, the clinical use of the appropriateness criteria has not become standard of practice for physicians [6]. Overall, approximately $64 \%$ of stress studies are appropriate. Approximately $14 \%$ of SPECT and $18 \%$ of stress echocardiography studies are performed for inappropriate indications, and approximately $10 \%$ of all patients are unclassifiable [6]. 
Table 1 Pretest probability of CAD according to age, gender and chest pain

\begin{tabular}{|c|c|c|c|c|c|}
\hline $\begin{array}{c}\text { Age } \\
\text { (Years) }\end{array}$ & Gender & $\begin{array}{l}\text { Typical/Definite } \\
\text { Angina Pectoris }\end{array}$ & $\begin{array}{c}\text { Atypical/ Probable } \\
\text { Angina Pectoris }\end{array}$ & $\begin{array}{l}\text { Nonanginal } \\
\text { Chest Pain }\end{array}$ & Asymptomatic \\
\hline \multirow[t]{2}{*}{$<39$} & Men & Intermediate & Intermediate & Low & Very low \\
\hline & Women & Intermediate & Very low & Very low & Very low \\
\hline \multirow[t]{2}{*}{$40-49$} & Men & High & Intermediate & Intermediate & Low \\
\hline & Women & Intermediate & Low & Very low & Very low \\
\hline \multirow[t]{2}{*}{$50-59$} & Men & High & Intermediate & Intermediate & Low \\
\hline & Women & Intermediate & Intermediate & Low & Very low \\
\hline \multirow[t]{2}{*}{$>60$} & Men & High & Intermediate & Intermediate & Low \\
\hline & Women & High & Intermediate & Intermediate & Low \\
\hline
\end{tabular}

In a prospective multicenter trial, the appropriateness criteria were evaluated in 7 physician practices of various size in partnership with United HealthCare. Overall, 14\% of all studies were inappropriate, most in asymptomatic individuals [5].

\section{Aim of the work}

Was to assess and compare appropriateness use criteria and the downstream use of resources as defined by patient outcomes in two different nuclear centers in Cairo.

\section{Methods}

\section{Patient Population}

\section{Inclusion criteria}

All patients older than 18 years undergoing SPECT in Kobry al Kobba military hospital and Ain Shams
University hospitals and capable of primary decision making were included throughout the period from February 2012 to august 2012 .

\section{Exclusion criteria}

1. Chronic illnesses or malignancy with estimated life expectancy of less than 1 year,

2. Unwilling to give informed consent,

3. Not accepting record access and phone call follow up.

The final cohort consisted of 442 patients.

\section{Methods}

After having a verbal consent of including the patients' data in the study, the following were recorded:

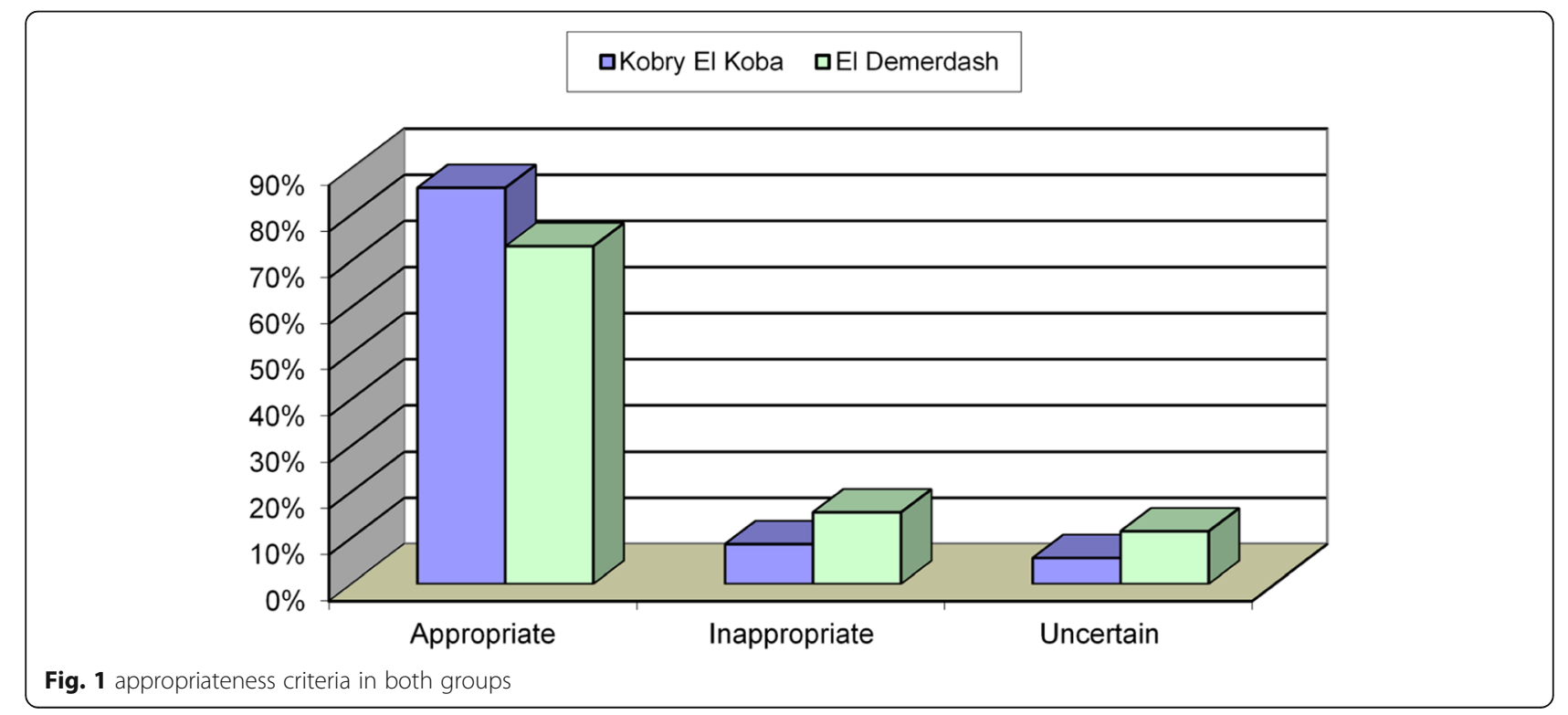


Table 2 Framingham Risk Score Calculation

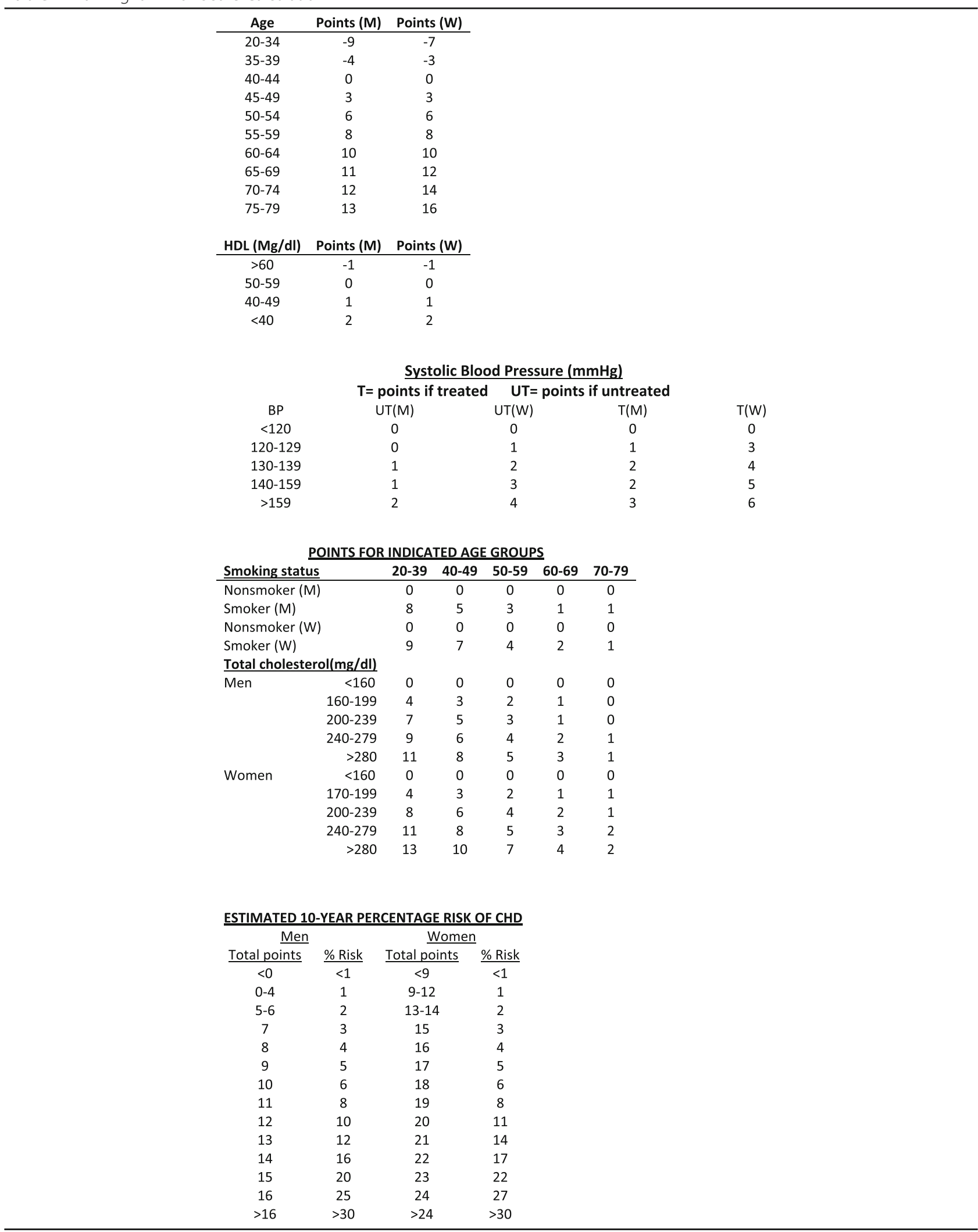


Table 3 Summed stress score according to cedars-sinai scoring system. Other centers may use alternative scoring systems with varying cutoffs [11]

\begin{tabular}{ll}
\hline Summed stress score & Indication \\
\hline$<4$ & Normal \\
$4-8$ & Mildly abnormal \\
$9-13$ & Moderately abnormal \\
$>13$ & Severely abnormal \\
\hline
\end{tabular}

\section{History taking:}

1. Age in years.

2. Gender.

3. Cardiovascular risk factors: arterial hypertension, diabetes mellitus, smoking and positive family history of premature cardiovascular diseases.

4. Known history of ischemic heart disease (defined as prior myocardial infarction demonstrated whether by ECG changes or revascularization history).

Pretest Probability of CAD: was determined for Symptomatic patients as in Table 1

With High meaning greater than $90 \%$ pretest probability. Intermediate: Between $10 \%$ and $90 \%$ pretest probability, low: Between 5\% and 10\% pretest probability, and very low: Less than $5 \%$ pretest probability. Modified from the ACC/AHA Exercise Testing Guidelines to reflect all age ranges [7].

The Framingham Risk Score (FRS): was done for patients with no symptoms and no history of ischemic heart disease as shown in Table 2

Pre-procedural ECGs were analyzed for:

- Presence of left bundle branch block.

- Healed infarction: e.g. Q waves in the ECG.

- Atrial fibrillation.

- Non-specific ST and T wave changes.

\section{Appropriateness use criteria: see Additional file 1}

Appropriateness was determined prospectively based on symptoms, pre-test likelihood of disease [8], and Framingham risk scores, FRS [9].

\section{Single photon emission computed tomography}

\section{- Stress-rest gated Tc99m Sestamibi scan:}

Table 4 Age and gender distribution of both groups

\begin{tabular}{|c|c|c|c|c|c|c|}
\hline & & \multicolumn{2}{|c|}{$\begin{array}{l}\text { Group I } \\
\mathrm{N}=245\end{array}$} & \multicolumn{2}{|c|}{$\begin{array}{l}\text { Group II } \\
\mathrm{N}=197\end{array}$} & \multirow{2}{*}{$\begin{array}{l}\text { Chi-square test } \\
\text { P-value }\end{array}$} \\
\hline & & No. & $\%$ & No. & $\%$ & \\
\hline \multirow[t]{2}{*}{ Gender } & Female & 91 & $37.10 \%$ & 11 & $5.60 \%$ & 0.000 \\
\hline & Male & 154 & $62.90 \%$ & 186 & $94.40 \%$ & \\
\hline Age & Mean \pm SD & \multicolumn{2}{|c|}{$56.45 \pm 9.47$} & \multicolumn{2}{|c|}{$56.49 \pm 9.80$} & 0.966 \\
\hline
\end{tabular}

Table 5 Risk factor distribution among both groups

\begin{tabular}{|c|c|c|c|c|c|}
\hline & \multicolumn{2}{|c|}{$\begin{array}{l}\text { Group I } \\
N=245\end{array}$} & \multicolumn{2}{|c|}{$\begin{array}{l}\text { Group II } \\
N=197\end{array}$} & \multirow{2}{*}{$\begin{array}{l}\text { Chi-square test } \\
P \text {-value }\end{array}$} \\
\hline & No. & $\%$ & No. & $\%$ & \\
\hline Smoking & 67 & $27.30 \%$ & 59 & $29.90 \%$ & 0.547 \\
\hline Hypertensive & 141 & $57.60 \%$ & 115 & $58.40 \%$ & 0.861 \\
\hline Diabetic & 92 & $37.70 \%$ & 76 & $38.60 \%$ & 0.851 \\
\hline
\end{tabular}

To detect the presence, severity and distribution of ischemia. For all stress imaging, the mode of stress testing was exercise for patients able to exercise.

For patients unable to exercise, pharmacologic stress testing was used. Further background on the rationale for the assumption of exercise is available in the ACC/ AHA 2002 guideline Update for Exercise Testing [7].

\section{Protocol}

A 2day protocol was used (day 1 for stress image and day 2 for rest one) by obtaining:

\section{a. Stress imaging:}

After fasting for at least 4 hours and abstinence from nitrates, beta blockers and calcium channel blockers; images were taken approximately 45-60 min after injection of 22-30 mCi of technetium99m Sestamibi through an indwelling intravenous cannula.

\section{Mode of stress}

1. Exercise stress testing: the radiotracer was injected at peak exertion at target heart rate ( $85 \%$ of age predicted maximum heart rate), proper analysis of stress data was done as follows:

- Protocol used.

- Duration of exercise.

- Percent of heart rate achieved.

Table 6 Indications of SPECT in both groups

\begin{tabular}{|c|c|c|c|c|c|}
\hline & \multicolumn{2}{|c|}{$\begin{array}{l}\text { Group I } \\
N=245\end{array}$} & \multicolumn{2}{|c|}{$\begin{array}{l}\text { Group II } \\
N=197\end{array}$} & \multirow{2}{*}{$\begin{array}{l}\text { Chi-square } \\
P \text { value }\end{array}$} \\
\hline & No. & $\%$ & No. & $\%$ & \\
\hline Screening for CAD & 130 & $53 \%$ & 159 & $79 \%$ & 0.000 \\
\hline Infarction & 35 & $14 \%$ & 45 & $23 \%$ & 0.02 \\
\hline $\mathrm{PCl}$ & 64 & $21.60 \%$ & 53 & $32.50 \%$ & 0.01 \\
\hline Viability & 26 & $11 \%$ & 5 & $3 \%$ & 0.001 \\
\hline CABG & 8 & $3.30 \%$ & 21 & $10.70 \%$ & 0.002 \\
\hline
\end{tabular}


Table 7 Pretest probability in both groups

\begin{tabular}{llll}
\hline & $\begin{array}{l}\text { Group I } \\
N=245\end{array}$ & $\begin{array}{l}\text { Group II } \\
N=197\end{array}$ & $P$ value \\
\hline High or intermediate pretest probability & $141(58 \%)$ & $155(79 \%)$ & 0.000 \\
Low pretest probability & $104(42 \%)$ & $42(21 \%)$ & 0.000 \\
\hline
\end{tabular}

- Blood pressure response.

- Cause of termination: Occurrence of chest pain or significant stress induced ECG changes.

2. Pharmacological stress test: indications:

- Inability to exercise.

- Left bundle branch block.

- Contraindication to exercise stress test e.g. severe bronchial asthma.

Pharmacological stress was done using Dipyridamole (infusion rate of $0.5 \mathrm{gm} / \mathrm{kg} / 4 \mathrm{~min}$ ) or Dobutamine (infusion rate of 10 to $40 \mathrm{ug} / \mathrm{kg} / \mathrm{min}$ ) and the radiotracer was injected at maximum dose or target heart rate.

\section{b. Rest images:}

Obtained 1day after stress image, approximately 1-1.5 hours after injection of $22-30 \mathrm{mCi}$ of technetium $99 \mathrm{~m}$ Sestamibi.

- One day rest imaging: was done to assess viability after the injection of $70 \mathrm{mg}$ of Trimetazidine 1 hour before injection of the radiotracer.

All radionuclide perfusion imaging indications used electrocardiogram (ECG) gating, whenever possible, with the determination of global ventricular function (i.e., left ventricular ejection fraction) and regional wall motion as part of the evaluation.

In the setting of a known acute coronary syndrome (ACS), the use of stress testing was performed in conjunction with pharmacologic stress testing, not exercise.

Table 8 Distribution of different categories according to FRS in both groups

\begin{tabular}{llll}
\hline & $\begin{array}{l}\text { Group I } \\
\mathrm{N}=245\end{array}$ & $\begin{array}{l}\text { Group II } \\
\mathrm{N}=197\end{array}$ & $P$ value \\
\hline Very low and low & $25(60 \%)$ & $6(50 \%)$ & 0.005 \\
Intermediate & $5(12 \%)$ & $2(17 \%)$ & \\
High & $12(28 \%)$ & $4(33 \%)$ & \\
\hline
\end{tabular}

Table 9 Pre-procedural ECG findings in both groups

\begin{tabular}{llll}
\hline & $\begin{array}{l}\text { Group I } \\
N=245\end{array}$ & $\begin{array}{l}\text { Group I } \\
N=197\end{array}$ & $P$ value \\
\hline Normal $n(\%)$ & $95(39 \%)$ & $41(21 \%)$ & NS \\
Pathological Q waves & $35(14 \%)$ & $45(23 \%)$ & NS \\
Non-specific changes & $94(38 \%)$ & $99(50 \%)$ & NS \\
AF & $3(1 \%)$ & $2(1 \%)$ & NS \\
LBBB & $5(2 \%)$ & $6(3 \%)$ & NS \\
RBBB & $9(4 \%)$ & $8(4 \%)$ & NS \\
IVCD & $4(2 \%)$ & - & \\
\hline
\end{tabular}

\section{Image acquisition and reconstruction}

Tomographic images were obtained using a rotatory dual head cardiac dedicated gamma camera (cardio MD, Phillips medical equipment's) in Ain Shams University hospitals and (dual head symbia II, Simens) in Kobry Al Kobba hospital with a low energy, general purpose collimator interfaced to a computer.

An arc of 180 degree was used, spanning from the 45 degree right anterior oblique projection to the $45 \mathrm{de}$ grees left posterior projection.

\section{Image interpretation}

Basal myocardial perfusion was assessed using the semiquantitative analysis on the 17-segment scoring system, as standardized by the cardiac imaging committee of the council on clinical cardiology of the American Heart Association [10].

\section{Nomenclature and location of the myocardial segments Perfusion analysis was translated into}

a- Segmental perfusion score: Perfusion was graded within each segment on a scale of 0 to 4 , with 0 representing normal perfusion and 4 representing a very severe perfusion defect.

b- The summed stress score (SSS): which was the sum of the 17 segmental scores from the stress images representing the extent and severity of stress perfusion abnormality, the magnitude of perfusion defects related to both ischemia and infarction, as shown in Table 3 [11].

Table 10 Mode of stress in both groups

\begin{tabular}{llll}
\hline & $\begin{array}{l}\text { Group I } \\
N=245\end{array}$ & $\begin{array}{l}\text { Group II } \\
N=197\end{array}$ & $P$ value \\
\hline Rest imaging $n(\%)$ & $26(11 \%)$ & $5(3 \%)$ & 0.001 \\
Treadmill stress $n(\%)$ & $151(62 \%)$ & $141(72 \%)$ & 0.66 \\
Pharmacological $n(\%)$ & $68(28 \%)$ & $51(26 \%)$ & 0.66 \\
\hline
\end{tabular}


Table 11 Development of symptoms during exercise test in both groups

\begin{tabular}{llll}
\hline & $\begin{array}{l}\text { Group I } \\
N=245\end{array}$ & $\begin{array}{l}\text { Group I } \\
N=197\end{array}$ & $P$ value \\
\hline Chest pain $n(\%)$ & $35(16 \%)$ & $75(39 \%)$ \\
Target heart rate $n(\%)$ & $143(94 \%)$ & $111(79 \%)$ & \\
\hline
\end{tabular}

c- The summed rest score (SRS): which was the sum of the 17 segmental scores from the rest images representing the extent of infarction.

d- The summed difference score (SDS): which was derived by subtracting SRS from the SSS and represents the extent and severity of stress induced ischemia. The digitalized images were evaluated by an experienced reader who was unaware of the clinical outcome and ECG findings of the patients.

\section{SDS score category [11]}

0-1 Normal

2-4 Mild ischemia

5-7 Moderate ischemia

$>7$ Severe ischemia

\section{Data management}

- Data was analyzed on an IBM personal computer, using statistical package for special science (SPSS) software computer program version 15 .

- Data was described using mean \pm standard deviation (SD) and frequencies according if they were quantitative or qualitative respectively.

- Independent student $\mathbf{T}$ test was used for comparing of quantitative variables between two groups. Chi square test was used for comparing of distribution of qualitative variables between different groups.

- The significance of the results was assessed in the form of $P$ value differentiated into:

- Non-significant: when $P$ value $>0.05$

- Significant: When $P$ value $<0.05$

- Highly significant: When $P$ value $<0.001$.

\section{Results}

In the present study, 442 patients derived from two territory hospitals in Cairo (Ain Shams university hospital and Kobry El-Kobba military hospital).

Table 12 Results of MPI in both groups

\begin{tabular}{llll}
\hline & $\begin{array}{l}\text { Group I } \\
N=245\end{array}$ & $\begin{array}{l}\text { Group II } \\
N=197\end{array}$ & P value \\
\hline Positive scan $n(\%)$ & $131(53 \%)$ & $120(61 \%)$ & \\
Negative scan $n(\%)$ & $114(47 \%)$ & $77(39 \%)$ & \\
\hline
\end{tabular}

Table 13 Appropriateness criteria in both groups

\begin{tabular}{|c|c|c|c|c|c|}
\hline \multirow[t]{2}{*}{ AUC } & \multicolumn{2}{|c|}{ Group I } & \multicolumn{2}{|c|}{ Group II } & \multirow{2}{*}{$\begin{array}{l}\text { Chi square } \\
P \text {-value }\end{array}$} \\
\hline & No. & $\%$ & No. & $\%$ & \\
\hline Appropriate & 179 & $73 \%$ & 169 & $86 \%$ & 0.005 \\
\hline Inappropriate & 38 & $16 \%$ & 17 & $8 \%$ & \\
\hline Uncertain & 28 & $11 \%$ & 11 & $6 \%$ & \\
\hline
\end{tabular}

The data of these patients were used to apply for the appropriateness criteria of performing myocardial perfusion scan in the two centers.

Based on the referral center results were divided into two groups:

- Group I: it included 245 patients derived from Ain Shams nuclear cardiology lab.

- Group II: it included 197 patients recruited from Kobry El-Kobba nuclear lab.

\section{Demographic data}

There were 340 males (77\%) and 102 females (23\%) with a mean age of $56.5+-9.8$ years. Males were dominant in the group derived from the military hospital compared to patients derived from Ain Sams university hospital. Table 4, Fig. 1.

\section{Risk factors}

Shown in Table 5.

\section{Indications to undergo the test}

Screening for CAD was the indication in 286 patients (65\%), post $\mathrm{MI}$ angina was the indication in 80 patients (18\%), post PCI angina was found in 117 patients (26\%) and in 29 patients $(6 \%)$ post CABG angina was the cause of referral.

Viability assessment was the referring cause in 31 patients (7\%).

As regards the cause of referral there was significant difference between results in both groups as shown in Table 6.

\section{Pretest probability}

By applying pretest probability, there were 296 patients with high or intermediate probabilities (67\%) and 146 patients with low probability for IHD (33\%) in the whole study group.

In group I, the low pretest probability was significantly higher than group II, whereas the high or intermediate probability was significantly higher than group I. Table 7.

\section{Framingham Risk Score (FRS)}

After excluding patients with documented CAD, there were 54 patients eligible for FRS (42 patients in group I and 12 patients in group II) 
Table 14 The number and percentage of each appropriateness criteria in both groups

\begin{tabular}{|c|c|c|c|c|}
\hline \multirow[t]{2}{*}{ AUC } & \multicolumn{2}{|c|}{ Group I } & \multicolumn{2}{|c|}{ Group ॥ } \\
\hline & No. & $\%$ & No. & $\%$ \\
\hline Detection of CAD, symptomatic with intermediate pretest probability, able to exercise. & 32 & 13.1 & 9 & 4.6 \\
\hline Detection of CAD, symptomatic with intermediate pretest probability, unable to exercise. & 9 & 3.7 & 3 & 1.5 \\
\hline Detection of CAD, symptomatic with high pretest probability. & 52 & 21.2 & 36 & 18.3 \\
\hline Risk assessment, post revascularization. & 19 & 7.8 & 67 & 34 \\
\hline Risk assessment, with known chronic stable angina and coronary stenosis. & 31 & 12.7 & 48 & 24.4 \\
\hline Detection of CAD, asymptomatic, high FRS & 8 & 3.3 & & \\
\hline Viability & 26 & 10.6 & 6 & 3 \\
\hline Evaluation of ventricular function, with use of cardiotoxic drugs & 2 & 0.8 & & \\
\hline Detection of CAD, symptomatic, with low or intermediate FRS. & 35 & 14.3 & 10 & 5.1 \\
\hline Known $C A D$, prior test result with normal coronary angiography & 2 & 0.8 & & \\
\hline Detection of CAD, symptomatic with low pretest probability. & & & 3 & 1.5 \\
\hline Post revascularization, asymptomatic. & 1 & 0.4 & & \\
\hline Risk assessment, known CAD. & 3 & 1.2 & 2 & 1 \\
\hline Risk assessment, post revascularization. & 25 & 10.2 & 9 & 4.6 \\
\hline Acute coronary syndrome, primary PCl, asymptomatic. & & & 4 & 2 \\
\hline
\end{tabular}

High and intermediate risk profile were significantly higher in group II s compared to group I. Table 8.

Pre-procedural ECG: shown in Table 9.

\section{Myocardial perfusion imaging}

There was no significant difference between both groups as regards the mode of stress used and procedural findings; Table 10, 11,12.

\section{Appropriateness use criteria}

Appropriateness use criteria in both centers shown in Tables 13, 14, 15.

\section{Discussion}

The objective of the current study is to identify clinical value of appropriateness use criteria in various patient

Table 15 The number and percentage of each appropriateness criteria in relation to results of MPI in both groups

\begin{tabular}{|c|c|c|c|c|c|c|c|}
\hline & & \multicolumn{4}{|c|}{ SPECT } & \multicolumn{2}{|c|}{ Chi-square test } \\
\hline & & \multicolumn{2}{|c|}{ Negative } & \multicolumn{2}{|c|}{ Positive } & \multirow[t]{2}{*}{$\overline{x^{2}}$} & \multirow{2}{*}{$\begin{array}{l}P \text { - } \\
\text { value }\end{array}$} \\
\hline & & No. & $\%$ & No. & $\%$ & & \\
\hline \multirow[t]{3}{*}{ Group I } & Appropriate & 77 & $67.50 \%$ & 102 & $77.90 \%$ & 14.479 & 0.001 \\
\hline & Inappropriate & 28 & $24.60 \%$ & 10 & $7.60 \%$ & & \\
\hline & Uncertain & 9 & $7.90 \%$ & 19 & $14.50 \%$ & & \\
\hline \multirow[t]{3}{*}{ Group II } & Appropriate & 62 & $80.50 \%$ & 107 & $89.20 \%$ & 5.130 & 0.077 \\
\hline & Inappropriate & 11 & $14.30 \%$ & 6 & $5.00 \%$ & & \\
\hline & Uncertain & 4 & $5.20 \%$ & 7 & $5.80 \%$ & & \\
\hline
\end{tabular}

and physician groups and to focus on downstream use of resources in relation to appropriateness.

This study evaluated SPECT appropriateness criteria in a diverse patient population. It included all patients undergoing SPECT in Kobry al Kobba military hospital and Ain Shams University hospitals throughout the period from February 2012 to august 2012.

It was noted that men were predominantly higher than women with $77 \%$ versus $23 \%$ respectively. Furthermore, men were higher in the group of Kobry Al Kobba military hospital (94\%) than patients of Ain Shams University $(62 \%)$.

This is higher than the results found by Regina et al. who investigated 570 patients with $55 \%$ of men and 45 $\%$ of women [12].

Diabetes, hypertension and smoking were investigated in our study as risk factors for ischemic heart disease and we found that $28 \%$ of patients were smokers, $58 \%$ hypertensive patients and 38\% diabetics.

This is compared to Raymond J. et al., who investigated 284 patients undergoing SPECT imaging and found that $48 \%$ of patients were smoking, $71 \%$ with hypertension and $27 \%$ with diabetes [6].

Most of our patients had high or intermediate pretest probability $66 \%$. It was noted that more patients with high or intermediate pretest probability were found in Kobry Al Kobba military hospital (79\%) versus (58\%) in Ain Shams university hospital.

On the other hand Regina et al. 2011 found that 51\% of patients had low pretest probability and only $6 \%$ had high pretest probability [12]. 
FRS was calculated for asymptomatic patients with no history of CAD which predict 10-year incidence of CAD, most of the patients are in the low risk groups (57\%).

This is supported by Regina et al. who found that 51\% of the patients fall in the low risk category [12].

In the present study, the overall percent of appropriate studies was $78 \%$. This is within the range found by Gibbons et al. 2008 who investigated the performance of appropriateness criteria for stress SPECT in 284 patients and found that $64 \%$ of SPECT studies were appropriate.

Also, Regina et al. found overall appropriate studies in the range of $63 \%$ [12].

On the other hand, we found that the overall inappropriate studies were forming $10 \%$ of all the studies done.

This finding is within the range reported by Gibbons et al. and Regina et al. which was $(14 \%)[6,12]$.

In our work, the uncertain or unclassified studies were found to be $15 \%$ of all studies.

This is supported Gibbons et al. who found that $10 \%$ of his studies were unclassified, but our findings were higher than that reported by Regina et al. who reported a $3 \%$ of unclassified studies [6, 12].

As regards center related findings, it was notable that the uncertain and inappropriate studies were higher in the university nuclear lab than that done in the military nuclear lab (15\% versus $7 \%)$ respectively. This may be explained by the inclusion of more females in the university.

This finding was explained by Gibbons et al. who reported that almost $50 \%$ of inappropriate test were asymptomatic patients with a low FRS who were referred for screening for CAD [6].

The second large group of inappropriate tests was done in patients under consideration of intermediate risk surgery who had good exercise capacity and no or minor risk factors, and the third group of inappropriate patients were symptomatic patients with low pretest probability, and the final group were patients for low risk non-cardiac surgery [6].

These findings prove that specific scenarios may differ from institution to institution and the recognition of these general patterns in appropriateness criteria should be helpful to clinicians.

Women were more symptomatic that men and had a lower prevalence of known CAD.

\section{Limitations}

Smaller number of included patients derived from 2 centers only over a relatively short period.

The inherited defects of FRS and its applicability on different ethnic groups such as Egyptians.

\section{Conclusion}

Appropriateness criteria are effective in identifying appropriateness of SPECT in a diverse patient population. More appropriate studies were observed in patients obtained from both sides of examination.

This study demonstrates the application of appropriateness criteria to attempt quality improvement in the clinical use of stress cardiac imaging.

\section{Recommendations}

Other long-term studies that include larger number of patients.

We encourage others to perform similar studies in their own institutions, hospitals, and private practices. Such efforts are only a first step towards the ultimate goal of quality improvement in this area and thereby contribute to increased efficiency in our healthcare system.

\section{Abbreviations \\ SPECT: Single-photon emission computed tomography; MPI: Myocardial perfusion imaging; ECG: Electrocardiogram; CAD: Coronary artery disease; FRS: The Framingham Risk Score; SSS: Summed stress score; SRS: Summed rest score; SDS: summed difference score; $\mathrm{PCl}$ : Percutaneous coronary intervention; CABG: Coronary artery bypass graft}

\section{Acknowledgements}

Authors would like to thank all staff, assistants and residents in both hospitals without whose help doing study would have not been possible. We also like to thank administration in both hospital for facilitating collection of data.

\section{Authors contributions}

AA: contributed in assessing patients and doing stress tests, main role in writing manuscript. HM: role was collecting data, doing stress tests and follow up of patients, helped in manuscript writing. MR: role was interpretation of test data and helping in data collection and analysis. All authors have read and approved the manuscript.

\section{Funding}

No special funding sources were obtained.

\section{Availability of data and materials}

Tables summing up our data is included in the manuscript.

The datasets used and/or analyzed during the current study are available from the corresponding author on reasonable request.

\section{Ethics approval and consent to participate}

Ain Shams University ethical committee approval was obtained prior to doing research.

Verbal consent was obtained from all participants (veterinary officers and farmers). Verbal consenting was approved from ethical committees as no personal data was declared and our trial is an observational trial with no intervention done to the patients other than what was already to be done.

Consent for publication

Not applicable.

Competing interests

The authors declare that they have no competing interests.

Received: 16 July 2019 Accepted: 23 September 2019

Published online: 10 January 2020

References:

1. Brindis RG et al (2005) ACCF/ASNC appropriateness criteria for singlephoton emission computed tomography myocardial perfusion imaging 
(SPECT MPI): a report of the American College of Cardiology Foundation Quality Strategic Directions Committee Appropriateness Criteria Working Group and the American Society of Nuclear Cardiology endorsed by the American Heart Association. J Am Coll Cardiol 46(8):1587-1605

2. Lucas FL et al (2006) Temporal trends in the utilization of diagnostic testing and treatments for cardiovascular disease in the United States, 1993-2001. Circulation 113(3):374-379

3. Patel MR et al (2005) ACCF proposed method for evaluating the appropriateness of cardiovascular imaging. J Am Coll Cardiol 46(8):1606-1613

4. Ward RP et al (2007) American Society of Nuclear Cardiology review of the ACCF/ ASNC appropriateness criteria for single-photon emission computed tomography myocardial perfusion imaging (SPECT MPI). J Nucl Cardiol 14(6):e26-e38

5. Hendel, R.C., et al., ACCF/ASNC/ACR/AHA/ASE/SCCT/SCMR/SNM 2009 appropriate use criteria for cardiac radionuclide imaging: a report of the American College of Cardiology Foundation Appropriate Use Criteria Task Force, the American Society of Nuclear Cardiology, the American College of Radiology, the American Heart Association, the American Society of Echocardiography, the Society of Cardiovascular Computed Tomography, the Society for Cardiovascular Magnetic Resonance, and the Society of Nuclear Medicine. Circulation, 2009. 119(22): p. e561-87.

6. Gibbons R et al (2008) Application of appropriateness criteria to stress single-photon emission computed tomography sestamibi studies and stress echocardiograms in an academic medical center. J Am Coll Cardiol 51(13):1283-1289

7. Gibbons, R.J., et al., ACC/AHA 2002 guideline update for exercise testing: summary article. A report of the American College of Cardiology/American Heart Association Task Force on Practice Guidelines (Committee to Update the 1997 Exercise Testing Guidelines). J Am Coll Cardiol, 2002. 40(8): p. 1531-1540.

8. Gibbons RJ et al (1999) ACC/AHA/ACP-ASIM guidelines for the management of patients with chronic stable angina: a report of the American College of Cardiology/American Heart Association Task Force on Practice Guidelines (Committee on Management of Patients With Chronic Stable Angina). J Am Coll Cardiol 33(7):2092-2197

9. Berman DS et al (2009) Quantitative assessment of myocardial perfusion abnormality on SPECT myocardial perfusion imaging is more reproducible than expert visual analysis. J Nucl Cardiol 16(1):45-53

10. Klocke FJ et al (2003) ACC/AHA/ASNC guidelines for the clinical use of cardiac radionuclide imaging--executive summary: a report of the American College of Cardiology/American Heart Association Task Force on Practice Guidelines (ACC/AHA/ASNC Committee to Revise the 1995 Guidelines for the Clinical Use of Cardiac Radionuclide Imaging). Circulation 108(11):1404-1418

11. Hachamovitch $R$ et al (1996) Exercise myocardial perfusion SPECT in patients without known coronary artery disease: incremental prognostic value and use in risk stratification. Circulation 93(5):905-914

12. Druz RS, Phillips LM, Sharifova G (2011) Clinical evaluation of the appropriateness use criteria for single-photon emission-computed tomography: differences by patient population, physician specialty, and patient outcomes. ISRN cardiology 2011:798318-798318

\section{Publisher's Note}

Springer Nature remains neutral with regard to jurisdictional claims in published maps and institutional affiliations.

\section{Submit your manuscript to a SpringerOpen ${ }^{\circ}$ journal and benefit from:}

- Convenient online submission

- Rigorous peer review

- Open access: articles freely available online

High visibility within the field

- Retaining the copyright to your article

Submit your next manuscript at $\boldsymbol{\nabla}$ springeropen.com 